\title{
EL MOTIVO EXPLANATORIO EN LOS MITOS DE HUAROCHIRI
}

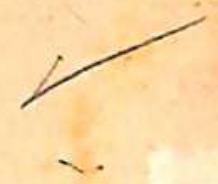

\author{
Prof. Dr. Hernan Trimborn
}

En una de sus obras conocidas (1) Roberto Lehmann-Nitsche, llamó la atención sobre el así denominado Motivo "etiológico" o "explanatorio" en los mitos de los pueblos, a la vez que compiló un vasto material de Sur-américa referente u este tema. La iniciativa del mencionado autor incita a seguir este criterio en los mitos de Huarochirí, transmitidos por el Dr. Francisco de Avila, los que he vertido y publicado por vez primera en su totalidad (2).

Pretendemos con ésto darnos cuenta cabal de los temas míticos donde es dable constatar un motivo "etiológico" o "explanatorio"; i. e. donde el mito también se presta para "apoyar con razones" los hechos naturales y culturales en su "estar presente" (Da-Sein) y en su estarasí (So-Sein). Puesto que, en el examen subsiguiente se separan los fenómenos naturales de los culturales, excluímos evidentemente un mitologema (mitologismo) de la exposición: el de la creación y de su 'causa prima" en que se basa $y$, que contemplado solo conceptualmente, también perteneciera dentro de la esfera de lo etiológico, aunque en su estrecha relación con los problemas de divinidades, será ob-
jeto de una investigación aparte y especial.

Abarcando de una ojeada las materias etiológicas, que nos legó Avila, hallamos sorprendidos que en esas quedan omitidos algunos mitologísmos importantes. Ante todo, el origen del nacer (alumbramiento) y el del morir, para los cuales en los mitos de muchos otros pueblos se busca dar una explicación, pero que aquí (3), sin más ni menos. se 1).-LEHMANN-NITSCHE, Robert: Studien zur suedamerikanischen Mythologle, Dle aetlo-
loglschen Motlve, Hamburg. 1939. 2).-TRIMBORN, Hermann: FRANCISCO DE AVILA. Dremonen und Zauber Im Inkarelch,
Lelpzig, 1939.

TRIMBORN. Hermann: Daemonen und Zauber in Inkurelch. Nachtraege zum khetsch3).-TRIMBorN, Hermann: Francisco de Avila, p. 76. 
los supone como condición esencial del género humano. Tampoco se aborda la procedencia de las plantas culturales (4), tal como se "lo explicas", v. g: -el origen del maíz y de la yuca-, con las extremidades corporales del hermanastro matado, en el mito de Pachacamaj de la costa peruana (5).'Sin duda alguna, estos indicios de deficiencia son dignos de ser considerados y que no pueden quedar inadvertidos creyéndose simplemente de que se trata de una transmisión incompleta.

\section{I}

Las manifestaciones tanto benéficas como funestas de la naturaleza: lluvias y granizadas, rayos y tempestades, los sufre el indígena direclamente como fenómenos vitales de potencias soberanas, que en esta forma con fuerzas superiores se comunican con lo terrenal. Este incidente emocional, desde el punto de vista de una cosmología explicativa intelectual, incluye una interpretación exploratoria de las manifestaciones mencionadas, cuyo sobrevenir, el hombre creyente concibe como un modo de obrar de entes antropromorfos, aunque trascendentales.

Por esta razón también es factible dirigirse a las divinidades con súplicas en demanda de lluvias. Se hacen patentes especialmente, PACHACAMAJ, y su pariente SUCIAHUILLCA como "pluvio dadores", a los que se encaminan, v. g: los CHECA con ofrendas de oro, plata y chicha-enterrándolas cerca de la Laguna de Suciahuillca (6). Sin embargo, también al hijo de Pariacaca, TUTAIQUIRI, piden los Checa lluvias, y con este propósito organizan el CHANCO, un baile mágico (7).

Empero el líquido fecundizador cuando se desata en forma de lluvia torrencial unida a granizadus yi rayos, se torng para el hombre en maldición; y es muy instructivo que en los mitos de Huarochirí, hasta con mayor frecuencia, se encuentre a la lluvia más bien como una maldición divina que como un beneficio excelso.

A manera de castigo por los pecaminosos desafueros insólitos y contranaturales / Hybris/ de TAMTAÑAMCA, un hombre acomodado de ANCHIKOCHA PARIACACA se lleva las casas de él y a sus llamas (8). Asimismo en forma de lluvia y granizo amarillo y rojo arrastra a los habitantes de HUAIQUIHUSA del valle de Huarochirí, por haberle negado el debido acatamiento (9), y se presenta como lluvia amarilla y roja, también en MACACALLA para destruir el villorio (10). Durante la lucha decisiva en la que vence a su adversario HUALLALLO CARHUINCHU, tal como corresponde a su quintuplicidad, hace llover en

4).-TRIMBORN, Fermann: Francisco de Avila, p. 76.

5).-LEHMANN-NITSCHE: p. 156.

6).-TRIMBORN: Francisco de Avila, p. 116.

7).-TRIMBORN: Franclsco de Avlla, p. 156.

8).-TRIMBORN: Francisco de Avlla, p. 87

9).-TRIMBORN: Franclsco d eAvlla, p. 88.

10).-TRIMBORN: Franclsco de Avlla, p. 125. 
amarillo y rojo, y relampaguear en cinco lugares distintos simultáneamente (11). Asimismo para cazar al demonio zoomorfo HUJI que fué soltado por Huallallo Carhuinchu, Pariacaca hace llover y relampaguear (12), y en su calidad de Dios-Huracón, se presenta en YARUTINI y se lleva a los habitantes (13).

También a los hijos de Pariacaca, manifiestamente temidos se le rinde culto y veneración como a divinidades de lluvia, de tempestades y de huracanes. Uno de ellos, Tutaiquiri, se hace presente por sobre los valles de SISICAYA y MAMA, en forma de una lluvia amarilla y roja. (14), mientras MACAHUISA socorre personalmente en forma de rayo y lluvia al Inca en su lucha contra los rebeldes (15). Pero también a LLOJLLAITHUANCUPA, como hijo de Pachacamaj (16) le era propia la facultad de producir rayos, tal como llegamos a saberlo del villorio de los Checa; LLAJSATAMPU (17).

Mientras el sib (clan) de Pariacaca se nos caracteriza esencialmente como un grupo de Divinidades de la Tempestad, Pachacamaj ostensiblemente es quien origina los movimientos sísmicos en los cuales manifiesta su ira de agitador del Universo.

Por eso, Pachacamaj que con propiedad recibe el calificativo de PACACUYUCHIJ (18), sólo se estremece cuando está iracundo, si con esa oportunidad volteara el cuerpo entero causaría la destrucción total del mundo. Como consecuencia se espantaba la gente cuando la tierra temblaba, recordándose la cólera de Pachacamaj (19). Distinta es la cuestión en Pariacaca, el agitado por tempestades, quien acá y allá puede presentarse en forma de aguacero o chubasco, mientras a Pachacamaj no le es dable desatar su enojo sobre algún lugar determinado; por más que sea capacitade sacudir el mundo entero, no tiene la facultad de distinguir entre amigos y enemigos. Por esta razón tampoco puede acudir en socorro del Inca, tal como lo hace el hijo de Pariacaca, Macahuisa, a su vez ayudando contra los rebeldes, porque el terremoto destruyera simultáneamente, a los soldados del emperador (20).

Motivos similares aduce Lehmann-Nitsche (21) respecto a algunos otros pueblos americanos. Entre los MUISCA fué CHIBCHACHUM el que origina terremotos, cuando mueve el globo terráqueo al cambiarlo de un hombro a otro. De igual modo se explican los sismos entre los Zapoteca porque su "Atlante" - ídolo en la cúspide de un collado dentro de la Laguna de Tehuantepec- mueve sus hombros. En cambio en-

11).-TRIMBORN: Franclsco de Avila, p. 92. 105.

12).-TRIMBORN: Franclsco de Avila, p. 107.

13).-TRIMBORN: Franclsco de Avlla, p. 125.

14).-TRIMBORN: Franclsco de Avlla, p. 100.

15).-TRIMBORN: Franclsco de Avlla, p. 118.

16).-TRIMBORN: Francisco de Avlla, p. 110.

17).-TRIMBORN: Francisco de Avlla, p. 112.

18).-TRIMBORN: Franclsco de Avlla, p. 117.

19).-TRIMBORN: Franclsco de Avila: p. 111.

20).-TRIMBORN: Franclsco de Avila, p. 118.

21),-LEHMANN-NITSCHE: p. 160. 
tre los Maya de Guatemala, se interpretaba el ruido producido por MAM durante el movimiento sísmico después de las primeras lluvias de los meses de Junio y Julio, como manifestación de enojo, por que las precipitaciones pluviales le mojaban su lecho (madriguera).

Entre todos los ejemplos aprovechados aporta más completamente la interpretación de los sismos como una expresión de la ira divina, la determinación del Motivo Explanatorio en el sentido de "explicación" de un fenómeno de la Naturaleza, que como una exégesis de la lluvia, granizo y rayo. Ia razón es que en éstos, de cierta manera, se trata de una aplicación del principio "impropia o apócrifa", porque los citados meteoros (fenómenos atmosféricos) aunque aparentan instrumentos de seres divinos, con esto nada se dice que ellos no existieran independientemente del facto que, el poder.mágico en las divinidades se sirviera de aquellos. Con una aplicación genuina del motivo etiológico, sin embargo, tenemos que habérnoslo en los ejemplos siguientes donde resulta una "explicación" mítica para el "estar-presente" o el "estar-asi" de un fenómeno natural.

$\Longrightarrow$ Así es que para los nativos resulta de confirmación la suposición de que la llama concebida como una constelación astral denominada YACANA o CHACANA (Orión), en horas de medianoche baje desde el firmamento para abrevar en las aguas del mar, debido a que el ccéano no se desborda e inunda la tierra (22).

$\Longrightarrow$ La razón del por qué el mar esté poblado con peces nos da a conocer el mito de CONIRAYA. Este, en su cólera sobre URPAIHUACHAJ, - la procreadora de palomas- arroja al mar los peces que ella criaba en una lagunita; desdecaquel ziempo hay peces en el océano (23).

No es de extrañar que entro los pueblos costeños ocupe un puesto destacado la interpretación de la aridez del ambiente con leyes existenciales divinas. Conforme a su conceptuación, CON indignado de los hombres que se pasaron de su culto al del Pachacamai, ya no manda llover (24). En cambio, como se había visto, en los mitos de Huarochirí, más pronunciadamente se patentizan las divinidades pluviodadores. Las montañas y los valles de Huarochirí en sus perfiles actuales surgieron a raíz de una disputa entre Pariacaca y Huallallo Carhuinchu durante la cual, el primero se desata en forma de una lluvia torrencial, de manera que, el paso de la época de Huallallo Carhuinchu a la del Pariacaca se halla relacionado con una catástrofe telúrica (25). En la lucha final entre ambos, Pariacaca se presenta en un descomunal agua-

22).-TRIMBORN: Franclsco de Avila, p. 129.

23).-TRIMBORN: Franclsco de Avlla, p. 80; comp. TELLO, Jullo C.: WIRA KOCIIA, "Inca", vol. I, Lima, 1923, p. 160 .

24).-Comp. BEUChat, Henr1: MaNUal DE arQUeOlogia americana, Madrld, 1918, p. 612.

BCHMIDT, Max: KUNST UND KULTUR VON PERU, Berlín, 1929, p. 121.

25).-TRIMBORN: Francisco de Avila, p. 88. 
cero "amarillo y rojo, que las aguas no pueden desaguar formándose como consecuencia la laguna de MULLUKOCHA (26).

Asimismo, en dos casos se explica el origen de los manantiales benéficos que surten los acueductos para la irrigación de los sembrados. Así la fuente de RATAJTUPI cerca de YAMPILLA brotó de la chicha desparramada descuidadamente por CAPYAMA (27) razón por la cual su origen es divino. Mientras tanto el líquido cristalino de la vertiente de Capyama debe su pureza a la manta humeral (Yakolla) de COLLQUIRI que en cierto modo le sirve de filtro cuando él pretende regularizar su caudal en exceso abundante y amenazador (28).

Un campo lucrativo y pletórico de fantasía para la aplicación de motivos etiológicos, como en muchos otros pueblos, representan tarr. bién las propiedades características de los animales.

Lo huraño y asustadizo del venado que con recelo huye del hombre, su cazador, en una fábula breve que da la impresión de ser fragmentaria, se lo motiva de manera siguiente: "También se cuenta que anteriormente los venados se alimentaban de carnes humanas. Empero cuando se habían multiplicado bastante deliberaron sobre cómo sería posible seguir alimentándose de gente. Uno de los animalejos tierno aún, malentendiendo el asunto tratado, preguntó: ¿de modo que la gente nos comerá a nosotros? Al oír esto los venados se desbandaron, y desde aquel día se tornaron er presa de los hombres" (29). De paso sea dicho, ese mito contiene a semejanza del capítulo IV "La Rebelión de los Utensilios", también el "Motivo del Mundo Trastrocado".

Por el fragmento anteriormente conocido procedente de Fco. de Avila ya nos es familiar el relato que la cola del zorro sea negra desde que ésta, cuando refugiado en el cerro HUILCAKOTO, se le había mojado en lás aguas del diluvio universal i (30). Ens relación con eso, Lehmann-Nitsche supone que originariamente no se trataba de un diluvio "pluvial" sino más bien de un diluvio "igneo", donde fué que se chamuscó la cola del zorro, y que posteriormente ese motivo algo raro fué sustituído por el diluvio universal. En este sentido remite también a los mitos de los Arecuná donde se refiere de la parte trasera chamuscada del Agutí, aunque por cierto se opone a eso el hecho de las patas y manos mojadas del mismo Parauacú entre los Caxinauá (Cashinahua). Con razón previene Lehmann-Nilsche que aquí, en eso como con frecuencia en otras partes, llega a expresarse la convicción de una transmisión por herencia de atributos adquiridos (31).

26).-TRIMBORN : Franclsco de Avila, p. 92.- Nachtraege, p. 149.

En Dávlla Brlcefio (Relaciones Geográflcas, vol. I, Madrid, 1881, p. 72) se basan:
Lehmann-Nitsche, p. 187 .

Jijón y Camáno, Jacinto: La religión del Imperio de lo Incas,

27).-TRIMBORN: Franclsco de Avila, p. 134.

28).-TRIMBORN: Francisco de Avila, p. 135.

(29) TRIMBORN: Francisco de Avila, p. 87.

30).-TRIMBORN: Franclsco de Avila, p. 81.

31).-LEHMANN-NITSCHE : p. IX, 31, 33, 41. 
Otras materias en sentido idéntico de una interpretación mítica de características animálicas, giian en torno del conocido mitologema sobre la bendición y la maldición de Coniraya (32).

Así, el hecho que el puma asalte a la llama, y que especialmente la llama del pecador le sirve como alimento, representa un obsequio que le hizo Coniraya (33); igualmente, adjudica al cóndor como comida cualquier clase de carroña, en particular, los guanacos y vicuñas muertas (34). Este motivo lo hallamos otra vez entre los Yuracare del río Mamoré, en la forma que el Urubú (Gallinazo) esté obligado al aprovechamiento de animales muertos (35). Al halcón como recompensa se le asignan los colibrís y otras aves como comida (36).

Manifiestamente se conceptúa aquí al Puma, al Cóndor y al Halcón como seres teriomorfos helíacos o solares, que en simpatía se relacionan con Coniraya, cuando éste se trastroca de un mendigo en Dios Sol. Por tal rázón se les contraponen, la mofeta (añás), el zorro y los papagayos como animales nocturnos cuyas propiedades peculiares se originan en la maldición de Coniraya. Con esta motivación mítíca, pues, la mofeta queda condenada a heder y ambular por las noches (37), el zorro, a ser enemigo despreciable e inútil para el hombre (38), y el papagayo, a graznar detestablemente y a vagar sin sosiego, lo odian y ahuyentan los hombres (39); merece atención la conceptuación antropocéntrica de los casos últimos.

Una posición destacada en el enmarcamiento de la interpretación mítica de los fenómenos naturales, finalmente ocupan las "interpretaciones" de las piedras antropomorfas o rocas y cerros así supuestos. La distribución casi universal de este motivo, prueba Lehmann-Nitsche (40) con numerosos ejemplos do piedras y cerros zoo- y antropomorfos en toda América Latina, Pdesdel México hastao Chile (41). Afín con eso también es la interpretación correspondiente a las estatuas monolíticas de Tiahuanacu que fueron consideradas por los indígenas posteriores como gente petrificada procedente de una edad del mundo anterior (42). Hallamos este motivo en los mitos de Huarochirí en los casos siguientes:

Ya en conexión con la persecución de CAHUILLACA y de su hijo concebido de Coniraya, los encontramos transformados en dos ro-

\footnotetext{
32).-COMP. TELLO, p. 160.

33).-TRIMBORN: Francisco de Avila, p. 79.

34).-TRIMBORN: Franclsco de Avlla, p. 79.

35).-LEHMANN-NITSOHE: p. 65.

36).-TRIMBORN: Francisco de Avila: p. $79-80$.

37).-TRIMBORN: Francisco de Avila, p. 79.

38).-TRIMBORN: Francisco de Avila, p. 79

39).-TRIMBORN: Francisco de Avila, p. 80.

40).-LEHMANN-NITSCHE: pp. $163-192$.

41).-COMP. KARSTEN, Rafael: THE CIVILIZATION OF THE SOUTH AMERICAN INDIANS, London-New York, 1926, p. 365;

KUTSCHER, Gerdt: CHIMU, Berlin, 1950, p. 97 (peruan. Nordëste).

42).THLLO, p. 164; KARSTEN, p. 338 .
} 
cas - las Islas de Pachacamac- que hoy las podemos ver todavía en el mar (43). Empero el mismo Coniraya se vuelve roca posteriormente cerca de la acequia de HUINCOMPA más arriba del villorrio CUPARA (44). Acontece ésto después de la aventura amatoria con la bella CHOKESUCO, originaria de Cupara, la que, a su vez, se petrifica también algo más abajo de Coniraya en el desagüe de la acequia denominada COCOCHALLA, donde la encontramos asentada como divinidad de la fecundidad (45).

En cambio otra piedra sobre el camino de San Damión a Anchikocha, que se hizo conocer como muslo y pubis de una mujer, se había considerado como la hija mayor del demonio Tamtañamca, a la que transformó en piedra HUATYACURI, el hijo de Pariacaca (46).

En la comarca de Yarutini se veneraba una piedra sagrada, a la cual el mismo Pariacaca dió por nombre "KAPAJ HUANCA" cuando destruyó el villorio que se negó al acatamiento, salvando a sólo un hombre y dándole vida perpetua, porque éste en el supuesto mendigo había reconocido al divino héroe cultural (47).

Se relaciona también con el motivo de Pariacaca la interpretación de numerosos bloques pétreos dispersos en el pedregal desértico de Macacalla, que el motivo explica como metamórfosis punitiva de los habitantes (48). Finalmente, encuéntrase motivo similar explanatorio en el RUCANAKOTO, el "Cerro Digital" fálico, considerado como asiento, es decir, como la petrificación de una divinidad de igual nombre. Erase que Rucanakoto iba entre las gentes, y fué el único que con su miembro viril descomunal pudo satisfacer completamente a la ninfómana diosa de la fecundidad, la CHAUPIÑAMCA la que más tarde se tornó en una piedra pentamorfa en la aldea de Mama (49).

\section{"Jorge Puccinelli Converso"}

\section{II}

A más de las aplicaciones del motivo explanatorio en las manifestaciones de un ambiente natural, también entre los indígenas del $\mathrm{Pe}$ rú, el "'estar-presente" y el "estar-asi" de las creaciones humanas, en especial, de los tradicionales hechos culturales, los hallamos atribuídos a un primigenio acontecer divino. Apenas precisa anotar que la diferenciación de grupos causales sólo existe en nuestra sistemática científica, pero no en el modo de pensar integral de los indígenas.

Tal como ocurre en muchos otros pueblos, la introducción inicial de hechos históricos $\mathrm{y}$ valores culturales, muchas veces se relacionan

43.-TRIMBORN: Francisco de Avila, p. 79. Comp: Lehmann-Nitsche, p. 187, error: Canlllaca.

44).-TRIMBORN: Franclsco de Avlla, p 90; comp. Jijón y Caamaño, p. 402. error: Umilo-
ma; Lehmann-Nitsche, p. 188 error: Umilopa.

45).-TRIMBORN: Francisco de Avila, p. 90; comp. Jijón y Caamafio, p. 402. error: Cococha;

Lehmann-Nitsche, pp. 187-8 error en el Slenakaka.

46).-TRIMBORN: Francisco de Avila, p. 68; comp. Lehmann-Nitsche, p 184.
47).-TRIMBORN: Francisco de Avila, p. 125.

48).-TRIMBORN: Francisco de Avlla, p. 126.

49).-TRIMBORN: Francisco de Avila, p. 98. 
con la aparición de algún "héroe cultural", cuyo rol con manifiesta superposición histórico-religiosa, desempeñan en los mitos de Huarochirí una vez Coniraya, - la divinidad de la fase antigua- y otra vez, Pariacaca, -la divinidad de la fase más joven. Coniraya, en otros tiempos, había creado las aldeas, los campos_y_los andenes de Huarochirí, y eso son sólo su verbo; también hizo manar a los acueductos por haber dejado caer al suelo meramente, la flor de un bejuco llamado PUPUNHA (50).

La divinidad pluviodadora de los ALLAUCA se denomina ANCHICARA, alrededor de quien se teje la graciosa leyenda amatoria con HUAILLAMA de SURCO. El y sus hijos son los responsables de que las aguas de las vertientes se almacenen en estanques y lagunas, y desde allí se desparramen por sobre la campiña allaucana (5I). El héroe cultural de los CONCHA se llama COLLQUIRI, siendo él quien hizo correr las fuentes, él quien construye diques, instituyendo el servicio de regadío ordenado con justeza y cúlticamente bajo vigilancia de un guarda-aguas ( 52 ).

Pero, el canal de irrigación que partía de la quebrada de Cocochalla a San Lorenzo de Quinti había sido prolongado hasta los campos de Cupara por Pariacaca personalmente (53). Se nos lo refiere en una bonita fábula cómo se había servido él de la colaboración de animales bondadosos, y de la emulación entre ellos, lo que nos proporciona la explicación de por qué el trazo del acueducto ostente una declinación repentina hacia abajo. - "Pues, le debían haber ayudado los Pumas, Zorros, Culebras y todas las Aves, limpiando y arreglando la acequia. En esta ocasión tuvieron una disputa los tigres y los pumas y demás animales sobre quién sería quienfuera alla cabeza para marcar la dirección, porque cada uno deseaba serlo. El zorro hizo prevalecer su opinión: "soy yo quien guiará", y de hecho se puso a la cabeza. Obtenida de esta manera la conducción, enfiló con precisión al cerro de San Lorenzo, cuando una perdiz apareció inopinadamente con su "pisi-pisi". Se asustó el zorro despeñándose con un "Huaj". Luego los demás con mucha ira decidieron que fuera la culebra quien se hiciese cargo de dirigente. Al no haberse precipitado el zorro, la acequia hoy se hallaría mucho más arriba de lo que se la vé e inclinada hacia abajo. Empero, el sitio de la caída del zorro se puede observar en nuestros días con mucha claridad, porque, debido a la caída, la acequia lleva su curso desviado hacia abajo".

La tradición de estabilidad efímera pronto se confunde con lo mitológico, con eso igualmente, las !eminiscencias históricas se cubren con el ropaje de un acontecer de tiempos inmemoriables (Urzeitgeschehen), también en los motivos mitológicos se nos "explica" la historia de cada una de las colectividades, de sus migraciones y de sus asentamien-

50)-TRIMBORN: Francisco de Avila, pp. $77-78$.

51)-TRIMBORN: Francisco de Avila, p. 130.

52)-TRIMBORN: Francisco de Avila, pp. 135 - 7.

53).-TRIMBORN: Francisco de Avila, p. 89. 
tos. Una transformación, tanto étnica como histórico-religiosa, cuya realidad no se necesita poner en duda, se había conservado en la tradición, y se entretejió en el rol de Pariacaca como portador cultural. Así es que la victoria alcanzada por Pariacaca sobre su contrincante Huallallo Carhuinchu, aportó a la expulsión de las tribus YUNGA hacia las regiones vallunas más bajas cuando antes igualmente moraban en las serranías $y$, al asentamiento de pobladores posteriores - los hijos de Pariacaca, a la vez que ayudó a abrirle al culto de Pariacaca (54).

Encontramos el mismo tema general, con digresiones de matices regionales. Se.refleja en el mito de Yarutini, cuando sus vecinos rehusaron su acatamiento a Pariacaca, por lo que el dios ofendido, en forma de Huracán, se los llevó de allí. Este hecho inicia la extinción de los pobladores antiguos, en lo local, dá comienzo al culto de Pariacaca (55).

En San Damián era familiar el mismo motivo con otra variante, ya que también en la aldea vecina de Macaacalla cuando se le negó sumisión en su primera visita a Pariacaca; por esta razón expulsó a sus pobladores, adjudicando la campiña a sus "hijos", haciéndose rendir homenaje después de haber transformado en piedras' a los pobladores precedentes (56). Manifiestamente se trata sólo de versiones locales, en las cuales se grabó en la memoria de los hombres, una transformación estructural histórica de la población, acompañada por la sustitución del culto de Huallallo por la veneración de Pariacaca. Se vincula en eso una tradición poco clara en lo temporal con el acontecer pretérito del mito, que de esta manera también nos explica la estructuración étnica de la región. En este sentido se fundamenta, con una escena atrayente, el curso de los límites de los Quinti Y Huarochirífrente a las tribus Yuca. - Pues, "Tutaiquiri, el hijo de Pariacaca, hallándose en una marcha victoriosa fué detenido con artimañas por una" hermana de Chokesuso, la diosa de la fertilidad, que sentada en su camino, con aparente casualidad, le mostraba los senos y las partes pudendas, para así seducirlo y demorarlo" (57).

El antagonismo histórico entre los Checa y los Quinti tiene su origen en un mítico pretérito. Un predecesor de los Quinti intentó engañar a uno de los Checa para conquistarse la gracia de Pariacaca. Sucede esto con ocasión de una caza para coger al demonio teriomorfo Huji, puesto en libertad por Huallallo en contra de Pariacaca. - "Muy lejos recién lo pudo coger un hombre de los Checa .... Un Quinti le dijo: "querido hermano, puedes alegrarte de haber podido cazarle, vé y ponte su cola por adorno a manera de una culebra y yo cargaré las carnes". Satisfecho el Checa se fué, pero el Quinti, tomando otro camino, se apresuraba para llevar la ruveva a Pariacaca. "Padre, - le dijoacabo de cogerle". Muy alegre Pariacaca alabó a CHUCPAICO, que

54).-TRIMBORN: Francisco de Avila, p. 94.

55).-TRIMBORN: Francisco de Avila, p. 125.

56).-TRIMBORN: Francisco de Avila ip. 125 - 6.

57).-TRIMBORN: Francisco de Avila, p. 157. 
así se llamaba el Quinti. Cuando poco después se acercaba el otro ofreciéndole a Pariacaca la cola, éste imprecó severamente a Chucpaico: "por qué me habías mentido, tú y todos los Quinti han de vivir en querella, y a tí y a tus hijos en adelante se les llamará "hediondos" (58).

Sin embargo, también nos refiere el mito, que a pesar de esta enemistad enraizada, por el culto unificador de Tutaiquiri, se llegó a una reconciliación posterior (59).

En la tribu de los Concha, les tradición mítica suministra una explicación de cómo quedó en poder del Ayllu HUALLA la laguna de YÂN$\mathrm{SA}$ en el decurso de su toma de asentamiento (60).

Hasta alcanza su sanción la última denominación del imperio de Tahuantisuyo, como lo llegamos a saber por el acontecer pretérito del mito; una visión regional lo retroconduce al hecho, que después de la victoria de Pariacaca sobre Huallallo se había convocado a todos los pueblos de los cuatro puntos cardinales para que rindiesen veneración a Pariacaca (61). Eso induce a la comprobación de que las convicciones y usos religiosos predominartes, sea en general o en determinados detalles, deben su validez obligatoria al mito conservado desde el $a$ contecer pretérito. Así es que en el mito se nos trasmite la tradición que el mismo Pariacaca después de su victoria sobre Huallallo Carhuinchu había dado la señal para su veneración fundando asimismo la institución del sacerdocio de los HUAJAS y YANCA (62).

Se desprende de eso que debía haber sido también Pariacaca quien anuló los sacrificios humanos en uso al servicio de la veneración a Huallallo Carhuinchu, contentándose con ofrendas más humanitarias. Esta transformación, tal vez histórica, se nos hace comprensible en los mitos de Huarochirí con la siguiente escena con las andanzas terrenales de Pariacaca. "Pues, asomócun hombre ques hallándose en peregrinación ritual había traído a uno de sus hijos, a más de MULLUS, Coca y Chicha de maní (tejti) para ofrecérselo todo a Huallallo. Fué interceptado por uno de los hijos de Pariacaca, que le preguntó a donde se dirigía para sacrificar, y le contestó: "padre, aquí a este mi hijo amado lo llevo a que sirva de alimento a Huallallo". Pariacaca le respondió: "Hijo mío, nada le lleves, más bien haz que regrese el joven ai pueblo; me brindarás los Mullus, la coca, la chicha de maní; empero mande regresar a casa a tu hijo" (63).

Tales degollaciones de inocentes al servicio del Huallallo Carhuinchu eran obligatorias desde el comienzo de la época de esa divinidad quien les había establecido, por decirlo así, como un tributo a percibir por ia creación de la humanidad. "Después de haber triunfado Huallalio Carhuinchu a continuación habría crèado al hombre, ordenándole

58).-TRIMBORN: Francisco de Avila, D. 107.

59).-TRIMBORN: Francisco de Avila, p. 100.

60).-TRIMBORN: Francisco de Avlla, p. 131

61).TRIMBORN: Francisco de Avlla, p. 131

62).-TRIMBORN: Franclsco de Avlla, pp. $100-7$; comp. Jijón y Caamaño. p. 323.

63).-TRIMBORN: Franclsco de Avila, pp. $91-3$. 
engendrar sólo dos hijos". A uno de ellos, ingirió Huallallo mismo, al otro el cual los padres más estimaban, han de criarlo ellos" (64).

A la inversa, ahora Pariacaca después de su "victoria" introduce nuevas formas cúlticas. Acontece de esa manera, que en conformidad a su mandamiento, conservado en el mito, se ofrece en sacrificio entre todas las comunidades circunvecinas, coca y llamas a su hijo CHOKEHUAMPU, quien se supone moraba entre Sisicaya y Sucia, más abajo de TUMNA (65). En cambio, a su rival Huallallo, quien fugó donde los HUANCA, quedó reducido a sacrificios de perros, lo que explica la costumbre entre los Huanca de comerlos (66).

Muchas otras usanzas y normas de conducta atribuye al mito a una institución divina. Fué el mismo Coniraya que en la huída mítica y persecución a Cahuillaca, pronuncia el interdicto de matar al cóndor, sentenciando toda transgresión para el futuro, con la muerte. - ("y si alguna vez te matara alguien, debe de morir también") - (67).

En conexión igual, el dios instaura el ritual conciliatorio que ha de observarse al ser muerto un puma o un halcón: - "y, cuando alguien te mate, anualmente te sacará en una gran fiesta, poniéndote en su cabeza (sc. máscara), y sacrificará una de sus llamas y, en honor tuyo hará bailes" (68); respectivamente: "Y, el hombre que alguna vez te mate, te ofrendará una de sus llamas, y en su baile te llevará como adorno en su cabeza" - (69). En ésta forma se explica los bailes de máscaras y los sacrificios de llamas como ritual de conciliación por un acontecer de tiempos inmemoriales.

El acontecer pretérito mitológico interpreta también al indígena el tránsito histórico-religioso de la creencia en el "cadáver viviente" que pervive obscuramente en la memoria-ti a la conceptuación del alma. La representación mítica lo inviste de un acontecer pretérito de la manera siguiente: Otros pretenden saber que en aquellos tiempos nada se sabía de Pariacaca ni de Carhuinchu, y antes de que ambos existiesen, los hombres se dirigían hacia una región superior para despertar en YAURILLANCHA, es decir, en la tal denominada HUICHICANCHA. Desde allí, pasados cinco dáas, regresaban a la tierra. Aquí solía esperarse el regreso del difunto, teniéndole preparadas comidas y bebidas. Cuando a su regreso pronunciaba las breves palabras: "ya regresé", se había regocijado con sus padres y hermanos con el pensamiento de no morir jamás para siempre.

"He allí, otra vez había muerto un hombre, y los padres, hermanos y su mujer le esperaban después de su deceso. Pero al quinto día, en el cual ya debía estar de regreso, no aparecía todavía. Recién al día siguiente, es decir, al sexto, retornó cuando sus padres, hermanos y su mu-

64).TRIMBORN: Francisco de Avila, p. 76.

65).-TRIMBORN: Francisco de Avila, p. 93.

66).-TRIMBORN: Francisco de Avila, pp. $93-4$.

67).-TRIMBORN: Francisco de Avila, p. 79.

68).-TRIMBORN: Francisco de Avila, p. 79.

69).-TRIMBORN: Francisco de Avila, p. 80. 


\section{$-146-$}

jer lo esperaban con enojo $y$, cuando por fin se presentó, su mujer de continuo le increpó: "¿por qué fuiste tan perezoso?, jotros regresan sin desmayo i y a mi me hiciste esperar envano". En su ira la mujer le arrojó una tusa o marlo de maíz a la ánima que regresaba. Pero ésta con leve ruido dió la vuelta inmediaiamente, y desde aquel tiempo nunca jamás un solo difunto había regresado a la tierra" (70).

Sin embargo, merece ser repetido que para la mayor parte de la materia mítica, la explicación para el "estar-presente" y "el estar así". precisamente en los casos civilizatorios y cúlticos en especial, se podrá ver en una institución remotísima por un "héroe cultural". Aquí ante todo se trata de personajes divinos, Coniraya y Pariacaca, donde en sus imágenes míticas se funden, el rol de una creación del orden natural, y el rol de una institución del orden humano.

Sea bien entendido que no todas las explicaciones causales, asentadas en las apuntaciones del Dr. Avila corresponden al criterio del motivo "explanatorio". Llegamos a saber que, según la creencia de los nativos, un nacimiento de gemelos o una "KORI", es la consecuencia de un pecado de los padres, él exigía una explicación, una purificación cúltica (71).

Lo mismo un alumbramiento "ATA", (i. e. de un niño con sorprendente pilosis fuerte) ha sido enviado por Pariacaca, para advertir preventivamente un nacimiento Kori (72). Empero, las interpretaciones dadas aquí no se hallan en el plano mítico, no son apoyadas en razones de un acontecer pretérito.

Por otra parte, encontramos en el mito mismo explicaciones, pero las que no ayudan en la interpretación de hechos naturales o culturales, y por lo tanto tampoco son "explanatorios"; v.g.: respecto al origen del hombre Urpaihuachaj, por el hecho que la hija menor de esta divinidad huya de los requerimientos seductorios de Coniraya en forma de una paloma (73). O tal vez, la historia del origen de los Concha (74) que, en lo temporal, se pierde en el arcano del espacio míti$\mathrm{co}$, sin que tal génesis tribial con un parentesco primigenio mitológico, significara una aplicación genuina del principio etiológico. Para deslindar con mayor exactitud, no es un motivo etiológico del mito, quizá, la creencia de una difunción puede ser la consecuencia de un pecado (75), v. g.: la transgresión del mandamiento que prohibe dar muerte a un determinado animal (76); pero sí, la implantación inmemorial (urzeitliche) de este nexo causal dentro del orden universal ético, lo que el mito de Huarochirí, en el caso mencionado, explica con la bendición Y la maldición de Coniraya.

Bonn, Diciembre de 1950.

70).-TRIMBORN: Francisco de Avila, p. 127

71).-TRIMBORN: Nachtraege, p. 159.

72).-TRIMBORN: Nachtraeger, p. 161

73).-TRIMBORN: Francisco de Avila, p. 80

74).-TRIMBORN: Francisco de Avlla, pp. 131 - 2. Nachtraege, pp. 155 - 6.

75).-TRIMBORN: Nachtraege, p. 159.

76).-TRIMBORN: Francisco de Avila, p. 79. 